\title{
Non-exercise estimation of $\mathrm{VO}_{2}$ max using the International Physical Activity Questionnaire
}

\author{
Susan M. Schembre, PhD, RD and \\ University of Hawai'i Cancer Center, Prevention \& Control Program, Honolulu, HI \\ Deborah A. Riebe, PhD \\ University of Rhode Island, Department of Kinesiology, Kingston, RI 02881
}

\begin{abstract}
Non-exercise equations developed from self-reported physical activity can estimate maximal oxygen uptake $\left(\mathrm{VO}_{2} \max \right)$ as well as submaximal exercise testing. The International Physical Activity Questionnaire (IPAQ) is the most widely used and validated self-report measure of physical activity. This study aimed to develop and test a $\mathrm{VO}_{2}$ max estimation equation derived from the IPAQ-Short Form (IPAQ-S). College-aged males and females $(n=80)$ completed the IPAQ-S and performed a maximal exercise test. The estimation equation was created with multivariate regression in a gender-balanced subsample of participants, equally representing five levels of fitness $(n=50)$ and validated in the remaining participants $(n=30)$. The resulting equation explained $43 \%$ of the variance in measured $\mathrm{VO}_{2} \max \left(\mathrm{SEE}=5.45 \mathrm{ml} \cdot \mathrm{kg}^{-1} \cdot \mathrm{min}^{-1}\right)$. Estimated $\mathrm{VO}_{2}$ max for $87 \%$ of individuals fell within acceptable limits of error observed with submaximal exercise testing (20\% error). The IPAQ-S can be used to successfully estimate $\mathrm{VO}_{2}$ max as well as submaximal exercise tests. Development of other population-specific estimation equations is warranted.
\end{abstract}

\section{Keywords}

estimation equation; cardiorespiratory fitness; maximal oxygen uptake; international physical activity questionnaire

Cardiorespiratory fitness (CRF) is inversely associated with the risk of developing cardiovascular disease, colon cancer, non-insulin dependent diabetes mellitus, osteoarthritis, osteoporosis, and obesity (Blair et al., 1989; LaMonte et al., 2000; Pate et al., 1995). The inclusion of estimates of CRF into large health-related databases, such as the National Health and Nutrition Examination Survey and the Behavioral Risk Factor Surveillance System could greatly enrich population-based research. Currently, standard tests of CRF assess oxygen uptake $\left(\mathrm{VO}_{2} \mathrm{max}\right)$, which represents the upper limit of aerobic exercise tolerance, by maximal exercise testing. Submaximal exercise testing can also be used to estimate $\mathrm{VO}_{2}$ max within $10-20 \%$ of actual $\mathrm{VO}_{2}$ max. However, measuring $\mathrm{VO}_{2}$ max by exercise testing requires in-person assessment and can be time consuming, cost prohibitive, and impractical in epidemiological studies or large clinical studies. Less time consuming methods of estimating $\mathrm{VO}_{2}$ max, including non-exercise regression equations, which incorporate highly validated measures of physical activity (PA), warrant consideration for replacement of submaximal exercise testing and/or use in large population based studies that would benefit from having an estimate of $\mathrm{VO}_{2}$ max.

Susan M. Schembre, PhD, RD, University of Hawai'i Cancer Center, Prevention and Control Program, 677 Ala Moana Blvd. Suite 200, Honolulu, HI 96813, sschembre@ crch.hawaii.edu. 
Estimates of $\mathrm{VO}_{2}$ max derived from regression equations that incorporate various measures of self-report PA have demonstrated similar standards of error as compared to submaximal exercise testing (Bradshaw et al., 2005; Duque, Parra, \& Duvallet, 2009; George, Stone, \& Burkett, 1997; Malek, Housh, Berger, Coburn, \& Beck, 2004, 2005; Matthews, Heil, Freedson, \& Pastides, 1999; Wier, Jackson, Ayers, \& Arenare, 2006). Although self-report PA measures are not specifically designed to assess CRF, many assess frequency, duration, and intensity of regular PA, which are directly related to CRF (McArdle, Katch, \& Katch, 2007). Particular focus has been paid to utilizing outcomes from the Baeck's leisure time activity questionnaire (Baecke, Burema, \& Frijters, 1982) or the Physical Activity Status Scale (PASS) developed by the National Aeronautics and Space Administration's (NASA) Johnson Space Center (Jackson et al., 1990). To our knowledge, there has been no attempt to develop similar estimation equations using the International Physical Activity Questionnaire (IPAQ) (Craig et al., 2003; Hagstromer, Oja, \& Sjostrom, 2006), which is one of the most highly validated and utilized physical activity questionnaires.

The IPAQ is a widely used measure of PA that asks questions regarding frequency and duration of activities of various intensities. PA outcomes can be reported continuously as metabolic equivalent minutes per week (MET-min·week $\left.{ }^{-1}\right)$. Several studies have demonstrated the IPAQ has comparable validation properties, relative to other self-report PA instruments, when tested against objective measures of PA $(r \approx 0.30)$ (Brown, Trost, Bauman, Mummery, \& Owen, 2004; Craig, et al., 2003; Ekelund et al., 2006; Faulkner, Cohn, \& Remington, 2006; Macfarlane, Lee, Ho, Chan, \& Chan, 2007; Mader, Martin, Schutz, \& Marti, 2006). Multiple studies have explored the association between IPAQ outcomes and measures of CRF in populations of various age (Fogelholm et al., 2006; Hagstromer, et al., 2006; Mader, et al., 2006; Papathanasiou et al., 2010; Rangul, Holmen, Kurtze, Cuypers, \& Midthjell, 2008). Significant associations have been small to moderate $(\mathrm{r} \approx 0.1-0.4)$ varying by $\mathrm{CRF}$ measurement methodology (maximal versus sub-maximal exercise testing). Generally, stronger associations were observed in studies using maximal versus sub-maximal exercise testing in younger rather than older populations $(\mathrm{r} \approx 0.3-0.4)$. Of the IPAQ outcomes, Vigorous-intensity PA has been most consistently associated with $\mathrm{CRF}$ with stronger associations $(\mathrm{r} \approx 0.21-0.43)$. Collectively, these findings suggest the IPAQ outcome(s), particularly Vigorous-intensity PA, could be used to estimate CRF without exercise testing.

The objective of this study was to develop and test an equation to estimate $\mathrm{VO}_{2}$ max using the most widely accepted PA questionnaire, the IPAQ, in young adult men and women. In addition to gender, other known covariates, which can be collected via questionnaires, will be tested for inclusion in the estimation equation including age, weight, height, body mass index (BMI). It is hypothesized that an equation using the IPAQ will be as accurate as submaximal exercise testing in estimating $\mathrm{VO}_{2} \max$. Successful demonstration of the equations validity and accuracy will suggest that the equation could be used in large, population-based studies for the inclusion of important data regarding CRF and will warrant further validation in other similar populations as well as the development of other population-specific CRF estimation equations using the IPAQ.

\section{Method}

\section{Participants}

Healthy men and women aged 18 to 25 years with a range of fitness levels were recruited to participate in the study. Individuals who were not 18 to 25 years of age or reported other medical conditions that could be negatively affected by a maximal exercise test (i.e. heart conditions, chronic obstructive pulmonary disease, or pregnancy) were excluded. Also those who met criteria for underweight or morbid obesity with a body mass index $(\mathrm{BMI})<18.5$ 
$\mathrm{kg} \cdot \mathrm{m}^{-2}$ or $>40.0 \mathrm{~kg} \cdot \mathrm{m}^{-2}$ were excluded from participation due to potential contraindications and identified smokers were excluded as to not bias results from maximal exercise test results. All participants provided written informed consent in accordance with the guidelines of the Institutional Review Board prior to beginning the study.

\section{Survey and Measures}

Physical activity-PA was assessed using the IPAQ-Short Form for population use (IPAQ-S) (IPAQ-Short Form, August 2002). Continuous IPAQ-S outcomes of Walking, Moderate Activity, and Vigorous Activity were calculated by the following IPAQ scoring protocol and reported in units of MET min.week ${ }^{-1}$ : Walking $=(3.3 \times$ walking minutes $\times$ walking days $)$; Moderate Activity $=(4.0 \times$ moderate activity minutes $\times$ moderate activity days $)$; Vigorous Activity $=(8.0 \times$ vigorous activity minutes $\times$ vigorous activity days $)$ (Sjöström et al., 2005).

Anthropometric assessment-Height without shoes was measured to the nearest 0.1 centimeters using a SECA wall mounted stadiometer. Weight as measured to the nearest 0.1 pounds using the HV-150K electronic floor scale, which was calibrated to a known weight. BMI was calculated as follows: body mass $(\mathrm{kg})$ divided by height $\left(\mathrm{m}^{2}\right)$. To estimate body fat, a three-site skinfold method was used (Jackson \& Pollock, 1978; Jackson, Pollock, \& Ward, 1980). Skinfold thickness was measured at the tricep, supralium, and thigh in the females and at the chest, abdominal, and thigh in the males. Body fat percentage was estimated using the Siri formula (Siri, 1961).

Maximal exercise testing-The Bruce treadmill protocol was used to measure $\mathrm{VO}_{2}$ max; (Roitman \& Herridge, 2001). Expired gases were analyzed for oxygen and carbon dioxide concentrations, and volume using a Medical Graphics CPXD metabolic cart. Prior to each test, the analyzers were calibrated using a known gas and the pneumotach was calibrated using a syringe of known volume. Breath-by-breath data were collected continuously throughout the test and then averaged over 30 -s periods. Heart rate was continuously measured using a Polar Heart Rate Monitor (Polar Electro O, Kempele, Findland). Ratings of perceived exertion (RPE) were assessed at the end of each stage and at maximal exercise using the Borg Rating of Perceived Exertion Scale (Borg, 1974, 1998). A test was considered maximal if subjects achieved two of the following criteria: (1) an RPE $\geq 17$; (2) a respiratory exchange ratio of 1.1 or higher; (3) a heart rate within 10 beats of the agepredicted maximal heart rate; and (4) a $\mathrm{VO}_{2}$ plateau with increasing workload.

\section{Statistical Analyses}

Descriptive statistics including means, standard deviations (SD), and skewness and kurtosis were performed for all continuous variables to assess for normal distribution of the data. It is not uncommon for the IPAQ-S outcomes to be non-normally distributed (Sjöström, et al., 2005). To normalize the PA data, square root transformation was applied to each of the continuous IPAQ-S outcomes. The transformed IPAQ-S data were used in all analyses but are presented as non-transformed data for ease of interpretation. All statistical analyses were performed using SPSS for Windows, version 16.0 (SPSS for Windows; version 16.0, 2008). Significance for all tests were set at a $\mathrm{p}<0.05$ level.

$\mathrm{A} \mathrm{VO}_{2}$ max estimation equation was derived using significant variables of interest determined by Pearson correlations within a subsample of study participants (derivation group). The derivation group was gender balanced and randomly selected to equally represent five fitness categories based on measured $\mathrm{VO}_{2} \max$. The remaining participants were used to validate the derived estimation equation. Differences between the derivation and validation subgroups for all variables were determined using independent $t$-tests. Within 
the derivation sample, Pearson correlations were conducted to explore associations between $\mathrm{VO}_{2} \max$, IPAQ-S outcomes, and potential covariates including age, weight, height, and BMI. Only variables that were significantly associated with measured $\mathrm{VO}_{2} \mathrm{max}$ and are assessable by self-report were considered for inclusion in the estimation equation.

The resulting estimation equation was derived using standard and stepwise multiple linear regression techniques. The ability of the regression equation to estimate measured $\mathrm{VO}_{2} \mathrm{max}$ accurately was examined using paired sample t-tests and Pearson correlations. BlandAltman plots (Bland \& Altman, 1986) were used to assess the degree of error between measured and estimated $\mathrm{VO}_{2}$ max and to determine if there was a pattern to the observed error. Validation analyses were conducted by repeating all tests of the estimation equation in and independent validation sample, representing all five fitness categories.

\section{Results}

A total of 80 healthy, college-aged males $(n=43)$ and females $(n=37)$ completed the study. The majority of participants were between the ages of 18 and 20 years $(76 \%)$ and White $(84 \%)$. The derivation subgroup $(\mathrm{n}=50)$ was gender-balanced and had a proportional representation of individuals from five fitness levels (ten participants per group; five males, five females) as designated by the American College of Sports Medicine (Thompson, Gordon, \& Pescatello, 2009). The validation subgroup $(n=30)$ was comprised of the remaining males and females ranging in fitness level from very poor to excellent/superior. Those in the derivation subgroup were younger than the validation subgroup $(\mathrm{p}=0.027)$. Participant characteristics are summarized in Table 1.

Pearson correlations among $\mathrm{VO}_{2} \mathrm{max}, \mathrm{PA}$, and participant characteristics indicated that gender, height, and Vigorous Activity were significant univariate correlates of measured $\mathrm{VO}_{2} \max$ (Table 2).

Two models were considered in the derivation of the $\mathrm{VO}_{2} \mathrm{max}$ estimation equation. The first model (Model 1) included gender, age, weight, height, and Walking, Moderate Activity, and Vigorous Activity. In Model 2, BMI was included rather than weight and height. In both models, standard multiple regressions indicated that only gender and Vigorous Activity had significant independent multivariate associations with $\mathrm{VO}_{2} \max$. To confirm these associations, regression analyses were repeated using stepwise regression that resulted in the same final model (Model 3). As expected, gender and Vigorous Activity remained in the model. Above and beyond the contribution of gender, Vigorous Activity contributed a large portion of the variance in measured $\mathrm{VO}_{2}$ max denoted by a significant change in $R^{2}\left(\Delta R^{2}=\right.$ $0.147, \mathrm{p}=0.001$ ). Model 3 explained $43 \%$ of the variance in measured $\mathrm{VO}_{2} \mathrm{max}$ and was selected as the final model for the derivation of the $\mathrm{VO}_{2}$ max estimation equation based on parsimony. Using the resulting unstandardized coefficients, $\mathrm{VO}_{2}$ max is estimated by the following equation where males $=1$ and females $=2$ and Vigorous Activity is calculated as MET-mins $\cdot$ week ${ }^{-1}$ : Estimated $\mathrm{VO}_{2} \max =47.749-[6.493 \times$ Gender $]+[0.140 \times($ Vigorous Activity) ${ }^{-2}$.

In the derivation subgroup, there was a strong paired-sample correlation coefficient $(\mathrm{p}<$ $0.001)$ and no significant difference between measured and estimated $\mathrm{VO}_{2} \max (\mathrm{p}=0.991)$ (Table 4). The standard error of estimate (SEE), was within the range of SEE reported for other non-exercise $\mathrm{VO}_{2}$ max estimation equations (Table 5) and well within the range of error $(10-20 \%)$ observed with submaximal exercise testing. The Bland-Altman plot (Figure 1A) for differences and averages of the estimated and actual $\mathrm{VO}_{2}$ max indicates $64 \%$ of the total sample fell within $1 \mathrm{SD}\left(5.45 \mathrm{~mL} \cdot \mathrm{kg}^{-1} \cdot \mathrm{min}^{-1}\right)$ of actual $\mathrm{VO}_{2}$ max. A total of $100 \%$ fell within $2 \mathrm{SD}\left(10.90 \mathrm{~mL} \cdot \mathrm{kg}^{-1} \cdot \mathrm{min}^{-1}\right)$. There was no evidence of systematic error as the mean 
of the differences between measured and estimated $\mathrm{VO}_{2}$ max equaled zero. However, the equation appears to underestimate (denoted by negative values) $\mathrm{VO}_{2} \mathrm{max}$ in fit individuals (categorized as good, excellent, and superior) by an average of $-9.2 \%$ (range $=-31.7 \%$ to + $9.2 \%$ ) and overestimate (denoted by positive values) $\mathrm{VO}_{2} \max$ in less fit individuals (categorized as very poor, poor, and fair) by $+9.7 \%$ (range $=-7.5 \%$ to $+19.8 \%$ ). A total of two individuals $(4 \%)$ had a total error $(\%)$ greater than the acceptable error estimated from submaximal exercise testing of $20 \%$.

In the validation subgroup, there again was a strong paired-sample correlation coefficient $r=$ $0.601, \mathrm{p}<0.001$ with no significant difference between measured and estimated $\mathrm{VO}_{2} \max (\mathrm{p}$ $=0.636$ ) (Table 4). Similarly, the standard error of estimate (SEE and SEE\%) were within the range of SEE reported for other non-exercise $\mathrm{VO}_{2}$ max estimation equations (Table 5) and within the $(10-20 \%)$ range of error observed with submaximal exercise testing. The Bland-Altman plot (Figure 1B) for differences and averages of the estimated and actual $\mathrm{VO}_{2}$ max indicates $67 \%$ of the total sample fell within $1 \mathrm{SD}$ of actual $\mathrm{VO}_{2}$ max and $97 \%$ fell within 2SD. The average underestimation in the fit group was $-11.2 \%$ (range $=-30.4 \%$ to + $8.7 \%$ ) and the overestimation in the unfit group was $+11.6 \%$ (range $=+5.4 \%$ to $+20.5 \%$ ). A total of four individuals (13\%) had a total error (\%) greater than the acceptable error estimated from submaximal exercise testing of $20 \%$.

\section{Discussion}

The purpose of this study was to develop an equation to estimate CRF using the IPAQ-S as the measure of PA in young adult men and women with varied fitness levels. Independent correlations between $\mathrm{VO}_{2}$ max and IPAQ outcomes were significant for gender, height, and Vigorous Activity. However, in multivariate analyses, only gender and Vigorous Activity contributed significantly to the estimation of $\mathrm{VO}_{2} \max$. The resulting estimation equation that explained $43 \%$ of the variance in $\mathrm{VO}_{2}$ max with an SEE $=5.45 \mathrm{~mL} \cdot \mathrm{kg}^{1} \cdot \mathrm{min}^{-1}(12.7 \%$ error). The maximum individual standard estimate of error was $11.59 \mathrm{~mL} \cdot \mathrm{kg}^{-1} \cdot \mathrm{min}^{-1}$. The resulting equation performed equally well in the derivation and validation subgroups. However, it appears to underestimate $\mathrm{VO}_{2}$ max in fit individuals and overestimate $\mathrm{VO}_{2}$ max in unfit individuals resulting in a total of six participants $(7.5 \%)$ with a disagreement between measured and estimated $\mathrm{VO}_{2}$ max of greater than $20 \%$, which is the acceptable range of error observed with submaximal exercise testing.

Several studies have reported associations between CRF and PA assessed by the IPAQ-S in multiple populations (Fogelholm, et al., 2006; Hagstromer, et al., 2006; Kurtze, Rangul, \& Hustvedt, 2008; Mader, et al., 2006; Papathanasiou, et al., 2010; Rangul, et al., 2008). Like this study, the measure of Vigorous Activity has been most consistently associated with $\mathrm{VO}_{2} \max$, whereas Walking and/or Moderate Activity often have no significant associations with CRF (Fogelholm, et al., 2006; Hagstromer, et al., 2006; Kurtze, et al., 2008; Papathanasiou, et al., 2010). Observed correlations between Vigorous Activity and CRF typically range from $r=0.21-0.43$ and vary by populations. The multivariate association between Vigorous Activity and measured VO2max in this study was within this range ( $\mathrm{r}=$ 0.359). Though correlations are consistently small to moderate, they support the potential for IPAQ outcomes, particularly Vigorous Activity, to be used to estimate $\mathrm{VO}_{2}$ max.

The addition of important covariates with known associations with CRF and/or PA is common in the development of $\mathrm{VO}_{2}$ max estimation equations that incorporate measures of PA. Most often variables such as gender, age, height, weight, and/or BMI are added to the model to improve the accuracy of the equation (Table 4). Inclusion of such variables is most appropriate when there is a significant amount of variation in the population characteristics. This study included a relatively homogeneous subsample of healthy college age males and 
females; therefore, fewer covariates were anticipated to contribute to the explanation of $\mathrm{VO}_{2}$ max, which allowed for a smaller sample size. As expected, the most significant covariate, namely gender, had a strong independent association with measured $\mathrm{VO}_{2} \mathrm{max}$. The finalized equation, which incorporated only a single covariate in addition to a measure of IPAQ-S Vigorous Activity, explained a large portion of variance in $\mathrm{VO}_{2} \mathrm{max}$ and performed as well as other equations that included a greater number of covariates.

A number of other studies have explored the feasibility of using self-report measures of PA to estimate CRF (Table 4). When tested for accuracy, each of the developed equations performed relatively well (\% SEE ranging between 7.8 and 15.5\%) with the exception of one, which was conducted in a sample of patients with chronic low back pain (Duque, et al., 2009). The degree of error in the estimation equation developed in this study is comparable to other similar equations (13.1\%) and performed similarly between the derivation and validation subgroups. Furthermore, the $\mathrm{VO}_{2}$ max estimation equation developed in this study is as accurate as predicting $\mathrm{VO}_{2}$ max using submaximal exercise tests. Typically, \% SEE values from submaximal tests by methods such as step tests, submaximal cycle ergometer test, or walk/run tests range within 10-20\% of actual $\mathrm{VO}_{2} \max$ (George, et al., 1997; Malek, Berger, Housh, Coburn, \& Beck, 2004) or within $10 \mathrm{ml} \cdot \mathrm{kg}^{-1} \cdot \mathrm{min}^{-1}$ for individual error (Heyward, 2006). In this study, $87 \%$ of the individual estimates of $\mathrm{VO}_{2}$ max were within $20 \%$ of actual $\mathrm{VO}_{2}$ max suggesting that, for most individuals, providing a limited amount of information (gender and self-reported PA) is as accurate as completing a submaximal exercise test.

It was noted that the equation tended to overestimate $\mathrm{VO}_{2}$ max in unfit individuals and underestimate $\mathrm{VO}_{2} \mathrm{max}$ in fit individuals. One potential explanation relates to the selection of the derivation subgroup. In regression, estimation errors can result from a statistical phenomenon referred to as "regression to the mean". Regression to the mean occurs in the presence of an imperfect correlation between two measures and results in the attenuation of extreme values closer to the population mean at a magnitude relative to the difference between a perfect correlation $(r=1.0)$ and the observed correlation $(r<1.0)$ (Davis, 1976). In this study, the $\%$ regression to the mean can be roughly calculated as $32.5 \%\left(\%_{\mathrm{RTM}}=100\right.$ (1-r)) and may explain a majority of the under- and overestimation observed in this study. While caution must be taken to not rely on absolute estimations of $\mathrm{VO}_{2}$ max from the derived equation, it should be noted that even with these errors, most individuals' estimates of $\mathrm{VO}_{2} \mathrm{max}$ were within the acceptable range of error.

This study and the $\mathrm{VO}_{2}$ max estimation equation derived in this study are strengthened by use of the IPAQ, which is the most widely used and well validated measure of PA to be used at the level of the population. Creating similar estimation equations with less reliable questionnaires could increase the potential for greater disagreement between estimated and observed measures of CRF in populations in which the PA questionnaire has not been validated. Furthermore, the study is greatly enhanced by the inclusion of a subsample of participants for the validation of the derived $\mathrm{VO}_{2}$ max estimation equation. Lastly, the use of Bland-Altman Plots to explore the nature of the error in estimating $\mathrm{VO}_{2} \mathrm{max}$ from the developed equations strengthened the study design. This method allows for the visual observation of how the equation estimates $\mathrm{VO}_{2} \max$ for the group at an individual level rather than the group level.

While the equation accurately estimated $\mathrm{VO}_{2}$ max in the study sample, the homogeneity of the group limits the generalizability of the equation to healthy, college-age males and females. Generally, it is recommended to use estimation equations in populations similar to those from which they were derived (Kleinbaum, 2007). It is unknown how accurate $\mathrm{VO}_{2}$ max estimates would be in more ethnically diverse populations or in older or less 
healthy populations. This sample was specifically selected to examine the accuracy of a $\mathrm{VO}_{2}$ max estimation equation derived from PA outcomes assessed by the IPAQ-S. Future research should be conducted to cross-validate this equation in other, similarly aged populations as well as to create new, population-specific $\mathrm{VO}_{2} \max$ estimation equations that use the IPAQ. Lastly, the accuracy of the equation is limited by the use of self-reported PA. Reporting issues related to PA assessment is likely due to the inability to correctly assess the intensity level of an activity or to accurately recall time spent being active (Montoye, 1996; Rzewnicki, Vanden Auweele, \& De Bourdeaudhuij, 2003). However, this is a limitation to any study utilizing a self-report measure of PA.

\section{Practical Recommendations}

The present study provides information not previously addressed in the literature regarding the use of the IPAQ to estimate $\mathrm{VO}_{2}$ max. When evaluated, the developed equation, which included only two easily assessable variables (gender and Vigorous Activity), was as accurate at estimating $\mathrm{VO}_{2}$ max as many other similarly derived equations as well as widely accepted submaximal exercise tests. This research demonstrates the IPAQ can be used to estimate $\mathrm{VO}_{2}$ max in sample college-aged males and females. Further validation of this equation in similar populations and the additional development of other population-specific $\mathrm{VO}_{2}$ max estimation equations using the IPAQ are warranted.

\section{Acknowledgments}

We would like to thank the research assistants who helped with data collection as well as the participants. A special thank you to the University of Rhode Island Department of Kinesiology for the use of equipment in the Human Performance Laboratory. During the preparation of this manuscript the author (SMS) was supported by the Nutritional and Behavioral Cancer Prevention in a Multiethnic Population postdoctoral fellowship supported by the National Cancer Institute (R25 CA 90956).

\section{References}

Baecke JA, Burema J, Frijters JE. A short questionnaire for the measurement of habitual physical activity in epidemiological studies. American Journal of Clinical Nutrition. 1982; 36(5):936-942. [PubMed: 7137077]

Blair SN, Kohl HW, Paffenbarger RS, Clark DG, Cooper KH, Gibbons LW. Physical fitness and allcause mortality. A prospective study of healthy men and women. Journal of the American Medical Association. 1989; 262(17):2395-2401. [PubMed: 2795824]

Bland JM, Altman DG. Statistical methods for assessing agreement between two methods of clinical measurement. Lancet. 1986; 1(8476):307-310. [PubMed: 2868172]

Borg GA. Perceived exertion. Exercise and Sport Science Reviews. 1974; 2(1):131-153.

Borg, GA. Borg's Perceived exertion and pain scales. Champaign, IL: Human Kinetics; 1998.

Bradshaw DI, George JD, Hyde A, LaMonte MJ, Vehrs PR, Hager RL, Yanowitz FG. An accurate $\mathrm{VO}_{2}$ max nonexercise regression model for 18-65-year-old adults. Research Quarterly for Exercise and Sport. 2005; 76(4):426-432. [PubMed: 16739680]

Brown WJ, Trost SG, Bauman A, Mummery K, Owen N. Test-retest reliability of four physical activity measures used in population surveys. Journal of Science and Medicine in Sport. 2004; 7(2): 205-215. [PubMed: 15362316]

Craig CL, Marshall AL, Sjostrom M, Bauman AE, Booth ML, Ainsworth BE, Pratt M, Ekelund U, Yngve A, Sallis JF, Oja P. International physical activity questionnaire: 12-country reliability and validity. Medicine and Science in Sports and Exercise. 2003; 35(8):1381-1395. [PubMed: 12900694]

Davis CE. The effect of regression to the mean in epidemiologic and clinical studies. American Journal of Epidemiology. 1976; 104(5):493-498. [PubMed: 984023] 
Duque IL, Parra JH, Duvallet A. A new non exercise-based $\mathrm{VO}_{2}$ max prediction equation for patients with chronic low back pain. Journal of Occupational Rehabilitation. 2009; 19(3):293-299.10.1007/ s10926-009-9180-5 [PubMed: 19421846]

Ekelund U, Sepp H, Brage S, Becker W, Jakes R, Hennings M, Wareham NJ. Criterion-related validity of the last 7-day, short form of the International Physical Activity Questionnaire in Swedish adults. Public Health Nutrition. 2006; 9(2):258-265. [PubMed: 16571181]

Faulkner G, Cohn T, Remington G. Validation of a physical activity assessment tool for individuals with schizophrenia. Schizophrenia Research. 2006; 82(2):225-231.10.1016/j.schres.2005.10.020 [PubMed: 16360305]

Fogelholm M, Malmberg J, Suni J, Santtila M, Kyrolainen H, Mantysaari M, Oja P. International Physical Activity Questionnaire: Validity against fitness. Medicine and Science in Sports and Exercise. 2006; 38(4):753-760. [PubMed: 16679993]

George JD, Stone WJ, Burkett LN. Non-exercise $\mathrm{VO}_{2}$ max estimation for physically active college students. Medicine and Science in Sports and Exercise. 1997; 29(3):415-423. [PubMed: 9139183]

Hagstromer M, Oja P, Sjostrom M. The International Physical Activity Questionnaire (IPAQ): a study of concurrent and construct validity. Public Health Nutrition. 2006; 9(6):755-762. [PubMed: 16925881]

Heyward, VH. Advanced fitness assessment and exercise prescription. 5. Champaign, IL: Human Kinetics; 2006.

International Physical Activity Questionnaire - Short Form. August. 2002 Retrieved from http://www.ipaq.ki.se/downloads.htm

Jackson AS, Blair SN, Mahar MT, Wier LT, Ross RM, Stuteville JE. Prediction of functional aerobic capacity without exercise testing. Medicine and Science in Sports and Exercise. 1990; 22(6):863870. [PubMed: 2287267]

Jackson AS, Pollock ML. Generalized equations for predicting body density of men. British Journal of Nutrition. 1978; 40(3):497-504. [PubMed: 718832]

Jackson AS, Pollock ML, Ward A. Generalized equations for predicting body density of women. Medicine and Science in Sports and Exercise. 1980; 12(3):175-181. [PubMed: 7402053]

Kleinbaum, DG. Applied regression analysis and other multivariable methods. 4. Belmont, CA: Brooks/Cole; 2007.

Kurtze N, Rangul V, Hustvedt BE. Reliability and validity of the international physical activity questionnaire in the Nord-Trondelag health study (HUNT) population of men. BMC Medical Research Methodology. 2008; 8(63)10.1186/1471-2288-8-63

LaMonte MJ, Eisenman PA, Adams TD, Shultz BB, Ainsworth BE, Yanowitz FG. Cardiorespiratory fitness and coronary heart disease risk factors: the LDS Hospital Fitness Institute cohort. Circulation. 2000; 102(14):1623-1628. [PubMed: 11015338]

Macfarlane DJ, Lee CC, Ho EY, Chan KL, Chan DT. Reliability and validity of the Chinese version of IPAQ (short, last 7 days). Journal of Science and Medicine in Sport. 2007; 10(1):45-51.10.1016/ j.jsams.2006.05.003 [PubMed: 16807105]

Mader U, Martin BW, Schutz Y, Marti B. Validity of four short physical activity questionnaires in middle-aged persons. Medicine and Science in Sports and Exercise. 2006; 38(7):1255-1266. [PubMed: 16826022]

Malek MH, Berger DE, Housh TJ, Coburn JW, Beck TW. Validity of $\mathrm{VO}_{2}$ max equations for aerobically trained males and females. Medicine and Science in Sports and Exercise. 2004; 36(8): 1427-1432. [PubMed: 15292753]

Malek MH, Housh TJ, Berger DE, Coburn JW, Beck TW. A new nonexercise-based $\mathrm{VO}_{2}(\max )$ equation for aerobically trained females. Medicine and Science in Sports and Exercise. 2004; 36(10):1804-1810. [PubMed: 15595304]

Malek MH, Housh TJ, Berger DE, Coburn JW, Beck TW. A new non-exercise-based $\mathrm{VO}_{2} \mathrm{max}$ prediction equation for aerobically trained men. Journal of Strength and Conditioning Research. 2005; 19(3):559-565. [PubMed: 16095416]

Matthews CE, Heil DP, Freedson PS, Pastides H. Classification of cardiorespiratory fitness without exercise testing. Medicine and Science in Sports and Exercise. 1999; 31(3):486-493. [PubMed: 10188755] 
McArdle, WD.; Katch, FI.; Katch, VL. Exercise physiology : energy, nutrition, and human performance. 6. Philadelphia, PA: Lippincott Williams \& Wilkins; 2007.

Montoye, HJ. Measuring physical activity and energy expenditure. Champaign, IL: Human Kinetics; 1996.

Papathanasiou G, Georgoudis G, Georgakopoulos D, Katsouras C, Kalfakakou V, Evangelou A. Criterion-related validity of the short International Physical Activity Questionnaire against exercise capacity in young adults. European Journal of Cardiovascular Prevention and Rehabilitation. 2010:380-386.10.1097/HJR.0b013e328333ede6 [PubMed: 19940775]

Pate RR, Pratt M, Blair SN, Haskell WL, Macera CA, Bouchard C, Buchner D, Ettinger W, Heath GW, King AC, et al. Physical activity and public health. A recommendation from the Centers for Disease Control and Prevention and the American College of Sports Medicine. Journal of the American Medical Association. 1995; 273(5):402-407. [PubMed: 7823386]

Rangul V, Holmen TL, Kurtze N, Cuypers K, Midthjell K. Reliability and validity of two frequently used self-administered physical activity questionnaires in adolescents. BMC Medical Research Methodology. 2008; 8(47)10.1186/1471-2288-8-47

Roitman, JL.; Herridge, M. American College of Sports Medicine's resource manual for Guidelines for exercise testing and prescription. 4. Philadelphia, PA: Lippincott Williams \& Wilkins; 2001.

Rzewnicki R, Vanden Auweele Y, De Bourdeaudhuij I. Addressing overreporting on the International Physical Activity Questionnaire (IPAQ) telephone survey with a population sample. Public Health Nutrition. 2003; 6(3):299-305. [PubMed: 12740079]

Siri, SE. Body composition from fluid spaces and density: analysis of methods. In: Broézek, J.; Henschel, A., editors. Techniques for measuring body composition. Washington, D.C.: National Academy of Sciences-National Research Council; 1961. p. 223-244.

Sjöström, M.; Ainsworth, B.; Bauman, A.; Bull, F.; Craig, C.; Sallis, J. Guidelines for Data Processing and Analysis of the International Physical Activity Questionnaire (IPAQ) - Short and Long Forms. 2005. Retrieved from http://www.ipaq.ki.se/scoring.pdf

SPSS for Windows. version 16.0. Chicago, IL: SPSS Inc; 2008.

Thompson, WR.; Gordon, NF.; Pescatello, LS. American College of Sports Medicine's guidelines for exercise testing and prescription. 8. Philadelphia, PA: Lippincott Williams \& Wilkins; 2009.

Wier LT, Jackson AS, Ayers GW, Arenare B. Nonexercise models for estimating $\mathrm{VO}_{2}$ max with waist girth, percent fat, or BMI. Medicine and Science in Sports and Exercise. 2006; 38(3):555561.10.1249/01.mss.0000193561.64152 [PubMed: 16540845] 

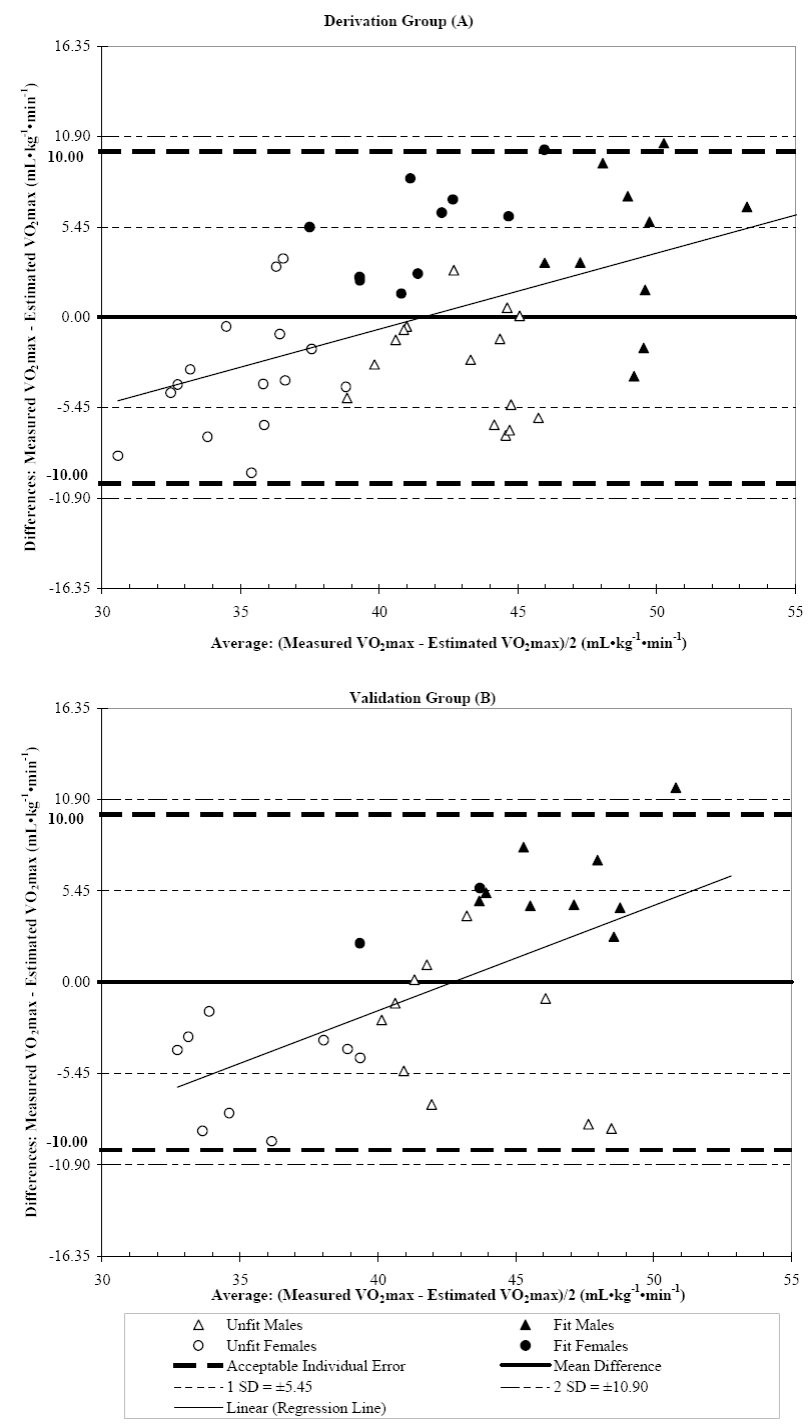

Figure 1. Bland Altman Plot $\mathrm{VO}_{2} \mathrm{max}$ Differences vs. Average

The difference between objectively measured $\mathrm{VO}_{2}$ max and Estimated $\mathrm{VO}_{2}$ max plotted against average of objectively actual $\mathrm{VO}_{2}$ max and Estimated $\mathrm{VO}_{2}$ max. Low fit individuals represent the very poor, poor, and fair fitness categories. High fit individuals represent the good, excellent, and superior fitness categories. Estimated $\mathrm{VO}_{2} \mathrm{max}=47.749-[6.493 \times$ Gender $($ males $=1$; females $=2)]+\left[0.140 \times(\text { Vigorous Activity })^{-2}\right]$. SEE $=5.45$ $\mathrm{ml} \cdot \mathrm{kg}^{-1} \cdot \mathrm{min}^{-1}$. Mean difference: $0.0 \mathrm{~mL} \cdot \mathrm{kg}^{-1} \cdot \mathrm{min}^{-1}$. Acceptable individual error: \pm 10 $\mathrm{ml} \cdot \mathrm{kg}^{-1} \cdot \mathrm{min}^{-1}$. A) Derivation group: $\mathrm{n}=32 ; 64 \%$ within $1 \mathrm{SD} ; \mathrm{n}=50 ; 100 \%$ within 2 SD. The difference between measurements was significantly correlated to average of the two measurements $(\mathrm{r}=0.478, \mathrm{p}=0.001)$. B) Validation group: $\mathrm{n}=20 ; 67 \%$ within $1 \mathrm{SD} ; \mathrm{n}=49$; $97 \%$ within 2 SD. The difference between measurements was significantly correlated to average of the two measurements $(r=0.567, \mathrm{p}=0.001)$. 


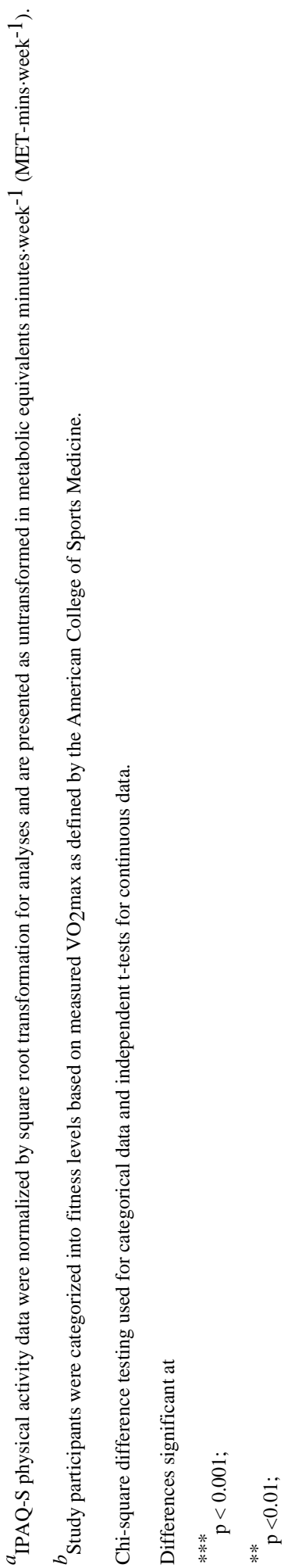




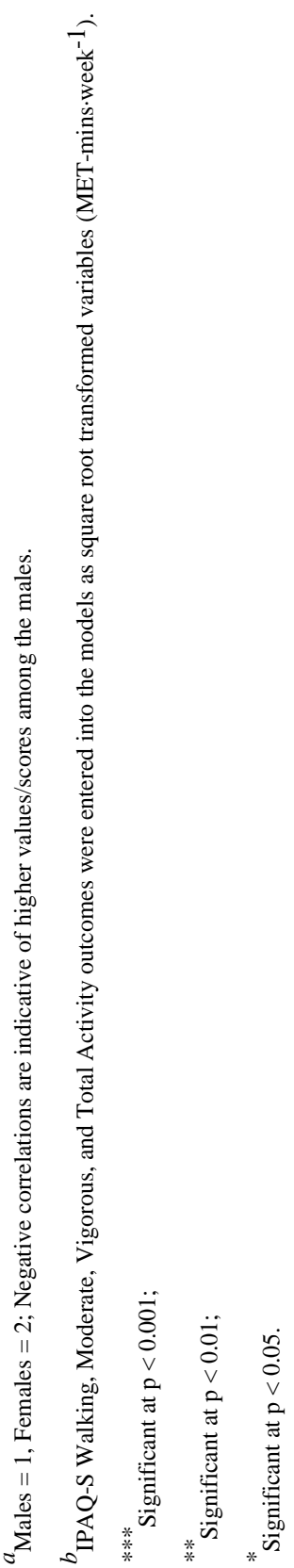

Meas Phys Educ Exerc Sci. Author manuscript; available in PMC 2011 September 15. 


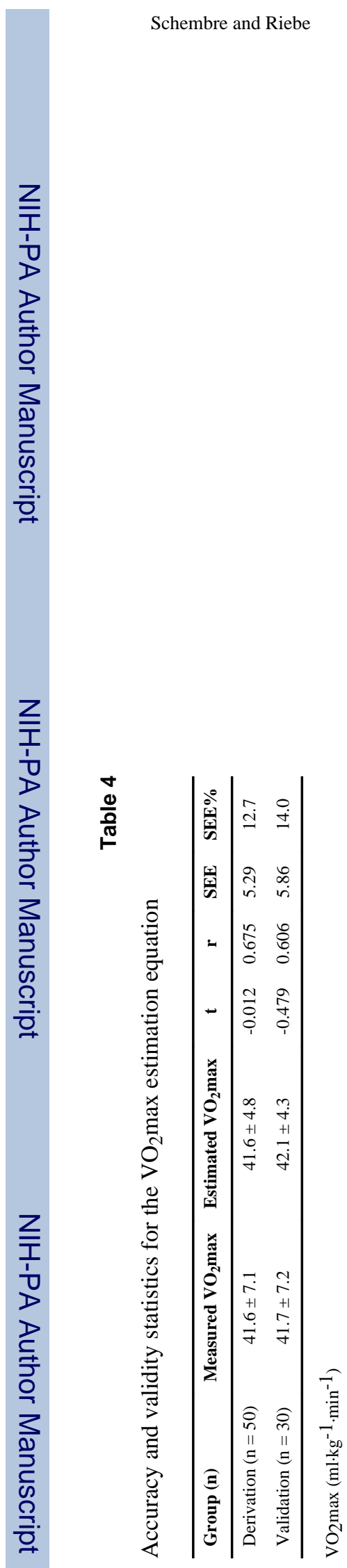

Meas Phys Educ Exerc Sci. Author manuscript; available in PMC 2011 September 15. 


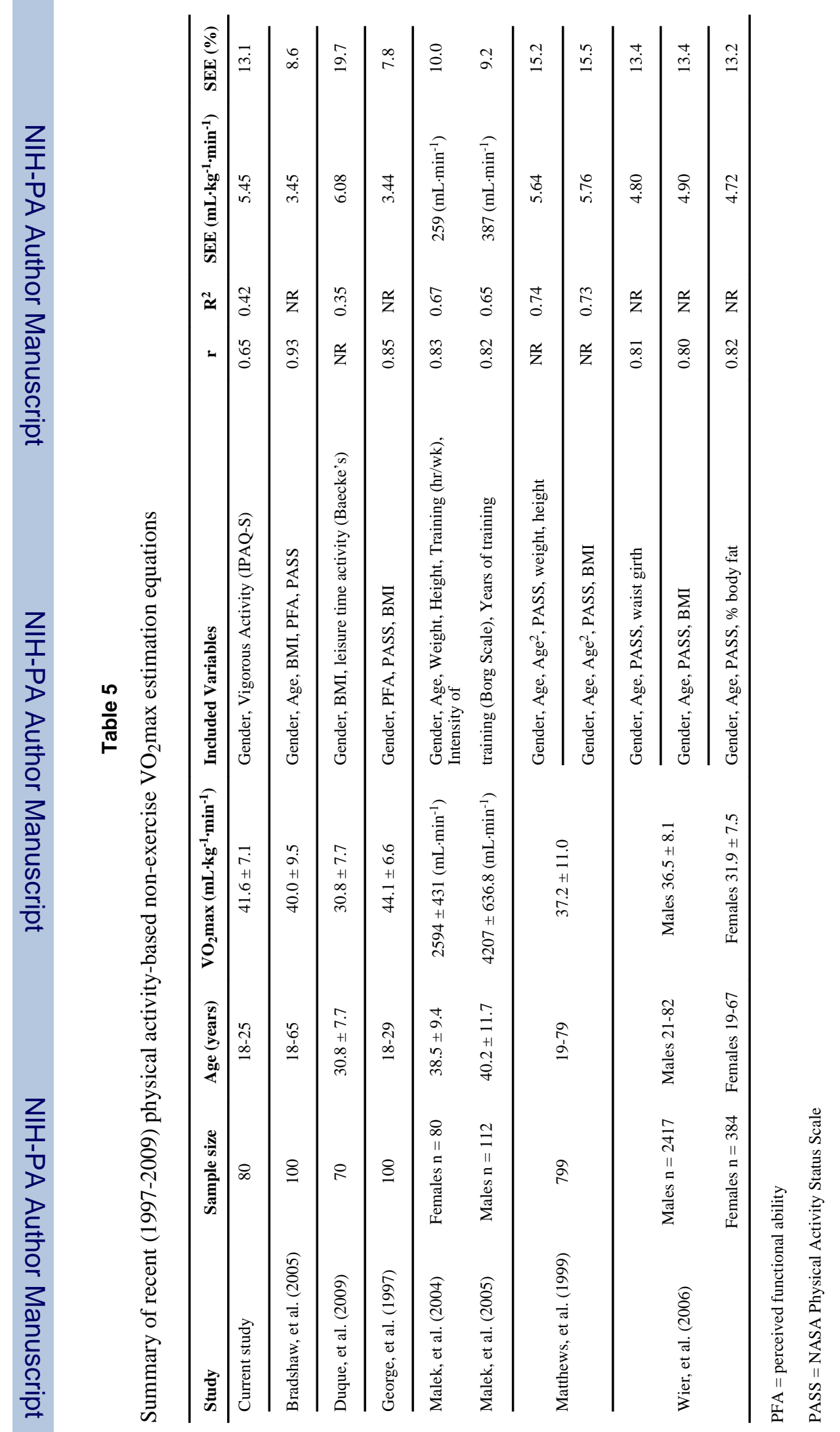

